\title{
Severity of Mining Accidents in Amasya, Turkey: An Epidemiological Analysis
}

\author{
Alper Çırakl1 ${ }^{1}$, Özgür Şekercan², Erdal Uzun ${ }^{3}$, Sedat Özmen ${ }^{4}$, Hasan Göçer ${ }^{5}$, Fatih Karaaslan ${ }^{6}$ \\ ${ }^{1}$ Department of Orthopedic and Traumatology, Faculty of Medicine, Ordu University, Ordu; \\ ${ }^{2}$ Department of Ear Nose and Throat, Suluova State Hospital, Amasya; \\ ${ }^{3}$ Department of Orthopedic and Traumatology, Faculty of Medicine, Erciyes University, Kayseri; \\ ${ }^{4}$ Department of Ophthalmology, Suluova State Hospital, Amasya; \\ ${ }^{5}$ Department of Orthopedic and Traumatology, Faculty of Medicine, Ondokuz May1s University, Samsun; \\ ${ }^{6}$ Department of Orthopedic and Traumatology, Faculty of Medicine, Bozok University, Yozgat, Turkey.
}

Received: 20 January 2020, Accepted: 04 April 2020, Published online: 31 August 2020

(C) Ordu University Institute of Health Sciences, Turkey, 2020

\begin{abstract}
Objective: Injuries that result from work-related accidents, which may cause permanent disabilities and death, have been increasing more in less developed and developing countries. Underground coal mining has been defined as very dangerous in danger classification about workplace, occupational health and safety. The purpose was to assess the state of mining accidents, which have caused serious injuries and deaths in Amasya, part of the Central Black Sea Region in Turkey.

Methods: We retrospectively examined 327 patients who were admitted to the emergency service of the Amasya Suluova State Hospital in the Central Black Sea Region, where there are many mines, in terms of mining accidents between 2008 and 2012 using ICD codes.

Results: All of the patients were male, and the mean age was $39.5 \pm 6.7$ years. The injuries took place mainly during the 8 am to $5 \mathrm{pm}$ shift (57.5\%), on a Thursday (19.6\%), in November (11.6\%), in Autumn (28.1\%) and in $2009(36.1 \%)$. Isolated, unilateral upper extremity injuries were the most common (36.4\%). A total of $54.1 \%$ of the accidents resulted in cuts, $34.6 \%$ resulted in fractures and $6.1 \%$ resulted in the loss of limbs, and $7.6 \%$ were transferred to a more equipped center. One patient who sustained upper extremity, chest and abdomen injuries died.

Conclusion: Mining accidents cause serious injuries and deaths in developing countries such as Turkey. We believe that collecting such regional data will contribute to the prevention of mining accidents.
\end{abstract}

Key words: Mining; accident; injury; epidemiology; analysis; Turkey

Suggested Citation: Cirakli A, Sekercan O, Uzun E, Ozmen S, Gocer H, Karaaslan F. Severity of Mining Accidents in Amasya, Turkey: An Epidemiological Analysis. Middle Black Sea Journal of Health Science, 2020; 6(2):152-157.

Address for correspondence/reprints:

Erdal Uzun

Telephone number: +90 (507) 2117999

ORCID-ID 0000000254563699

E-mail: nuzuladre@gmail.com
DOI: $10.19127 / \mathrm{mbsjohs} .677768$

Note: This study is presented as an oral presentation in Bone and Joint Congress in 2016 in Turkey 


\section{Introduction}

According to the World Health Organization's 2000 data, $9 \%$ of all deaths in the world occur due to injuries, and each year, 5.2 million people lose their lives due to this reason (Davas Aksan et al., 2010). Although injuries usually take place during industrial activities, they can also take place at home, in traffic, in a public space or during sport activities (Trybus et al., 2006). Injuries that result from work-related accidents, which may cause permanent disabilities and death, have been increasing more in less developed and developing countries (Lee et al., 2005).

Mining stands out as a difficult industrial area in Turkey and in the world in terms of work-related accidents. Underground coal mining has been defined as very dangerous in danger classification about work place, occupational health and safety (Feyer et al., 2001; McGwin et al., 2002; Kowalski-Trakofler et al., 2003; Bio et al., 2007; Kunda et al., 2013; Liu et al., 2015; Bloch et al., 2018; Wilson and Wetten, 2019). Despite regulations and raising attention towards the reduction of risk factors, the mining industry is still associated with higher rates of injury than other industries (Lee et al., 2005, Maiti et al., 2004; Komljenovic et al., 2007; Kunda et al., 2013; Wilson et al., 2020). In terms of occupational diseases and occupational accidents, mining has caused a great number of workers to become permanently disabled or to die (Feyer et al., 2001, Ghosh et al., 2004).

This epidemiological study analyzed the patients who were admitted to the emergency service of the Amasya Suluova State Hospital as a result of accidents that took place in mines, and the consequences of the accidents were assessed. To our knowledge, no epidemiological study has been published on mining accident from Turkey as one of the leading countries in the world in terms of occupational diseases and accidents. The aim of the current study was to assess the state of mining accidents, which have caused serious injuries and deaths, in Amasya, Turkey.

\section{Methods}

The injury records of 327 patients who were admitted to the emergency service of the Amasya Suluova State Hospital between 2008 and 2012 were analyzed using ICD codes. The data were analyzed in terms of the patients' age; the hour, day, month, season, year, and area that the mining accident took place; the severity (cut, fracture, loss of limb) of the injury; and the necessity of being transferred.

All data were collected from archive of Amasya Suluova State Hospital to measure. The time of injury was grouped into three shifts (between $12 \mathrm{pm}$ and 08 $\mathrm{am}$, between 08 am and $5 \mathrm{pm}$, and between $5 \mathrm{pm}$ and $12 \mathrm{pm})$. The ages of the patients were grouped as 16$24,25-34,35-44,45-54,55-64$ and over 65 years old. The injured areas were categorized into upper extremity, lower extremity, pelvis, spine, head, abdomen, chest, isolated or multiple with inhalation, while the severity of the injury was assessed categorized into cut, fracture, loss of limb or presence of transfer.

In this retrospective study, permission was given by the regional ethics review committee of the Faculty of Medicine, Samsun Ondokuz May1s University in 2014 (B.30.2.ODM.0.20.08/1187 OMU KAEK 2014/770). In accordance with the approval, informed consent from the patients was not required. All study procedures were performed in accordance with the recommendations outlined in the Declaration of Helsinki.

All of the obtained results were statistically analyzed. The data were entered into SPSS (SPSS Inc., Chicago, IL, USA) and tested for their conformity to a normal distribution using the ShapiroWilk test. The data that conformed to a normal distribution are reported as the mean \pm standard deviation, and the data that did not conform to a normal distribution are stated as the median (min$\max )$.

\section{Results}

All of the patients were male, and the mean age was $39.5 \pm 6.7$ years. Most of the patients $(180,55 \%)$ were between the ages of 35 and 44 years old, and they had at least 10 years of work experience.

Most of the injuries (188-57.5\%) took place during the 8 am to $5 \mathrm{pm}$ shift. The injuries primarily took place on Thursday $(64,19.6 \%)$, in November $(38,11.6 \%)$, during the Autumn $(92,28.1 \%)$ and in $2009(118,36.1 \%)$, whereas they least frequently took place on Sunday $(30,9.1 \%)$, in February (17, $5.2 \%)$, during the Summer $(71,21.7 \%)$ and in 2008 $(46,14.1 \%)$.

Isolated unilateral upper extremity injury was the most common injury $(119, \% 36.4)$. The number of patients with potential life-threatening injury and head trauma was $68(20.7 \%)$. It was observed that 177 $(54.1 \%)$ of the accidents resulted in a cut, 113 $(34.6 \%)$ resulted in a fracture and $20(6.1 \%)$ resulted in the loss of a limb. There were $25(7.6 \%)$ patients who were transferred to a more equipped, higher trauma level center for various reasons. A patient who had injured both of his upper extremities, chest and abdomen in 2012 died. The data are summarized with the figures (Figs. 1-5) 


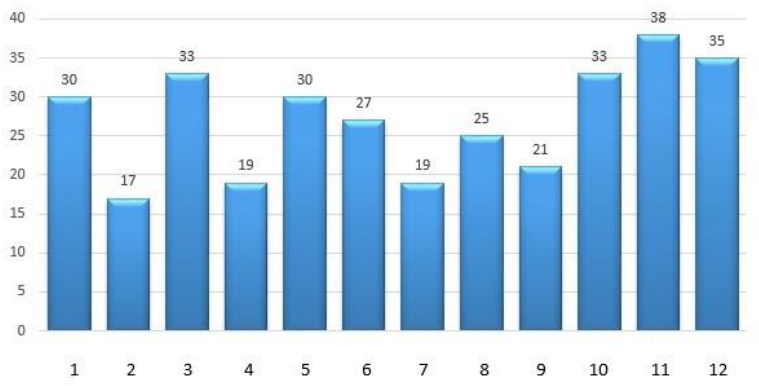

Figure 1. Distribution of cases by month. (the period from January to December is numbered from 1 to 12 )

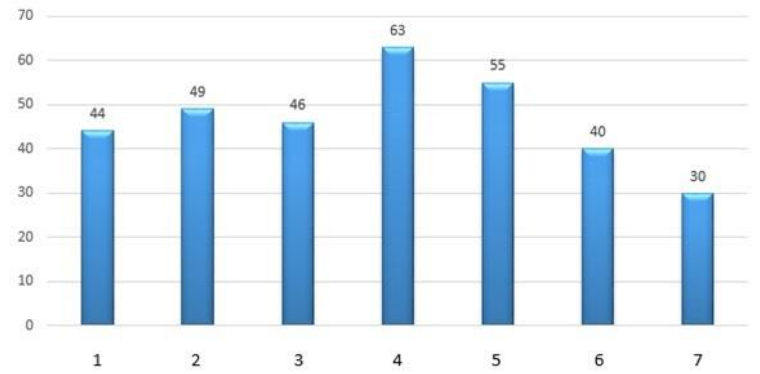

Figure 2. Distribution of cases by day. (the period from Monday to Sunday is numbered from 1 to 7 )

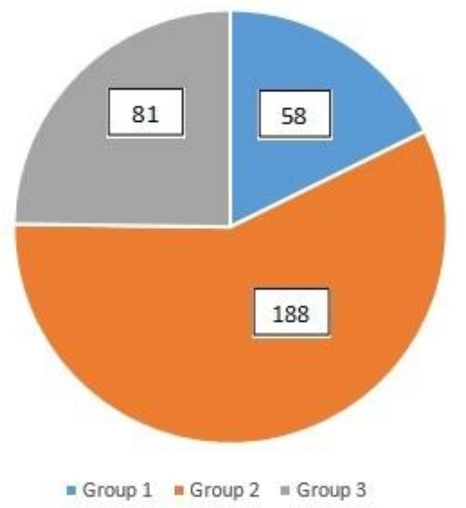

Figure 3. Distribution of cases by shift. (Group 1: 00-08 am, Group 2: 08 am-16 pm, Group 3: 16-00 pm)

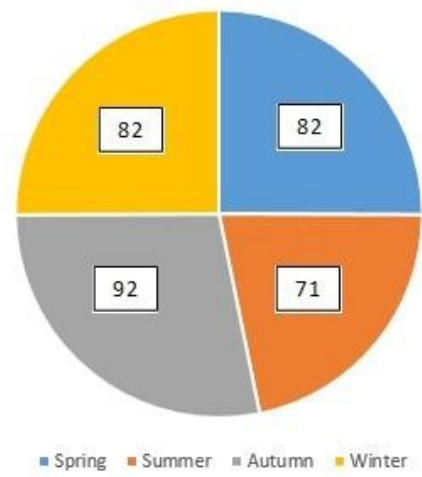

Figure 4. Distribution of cases by season

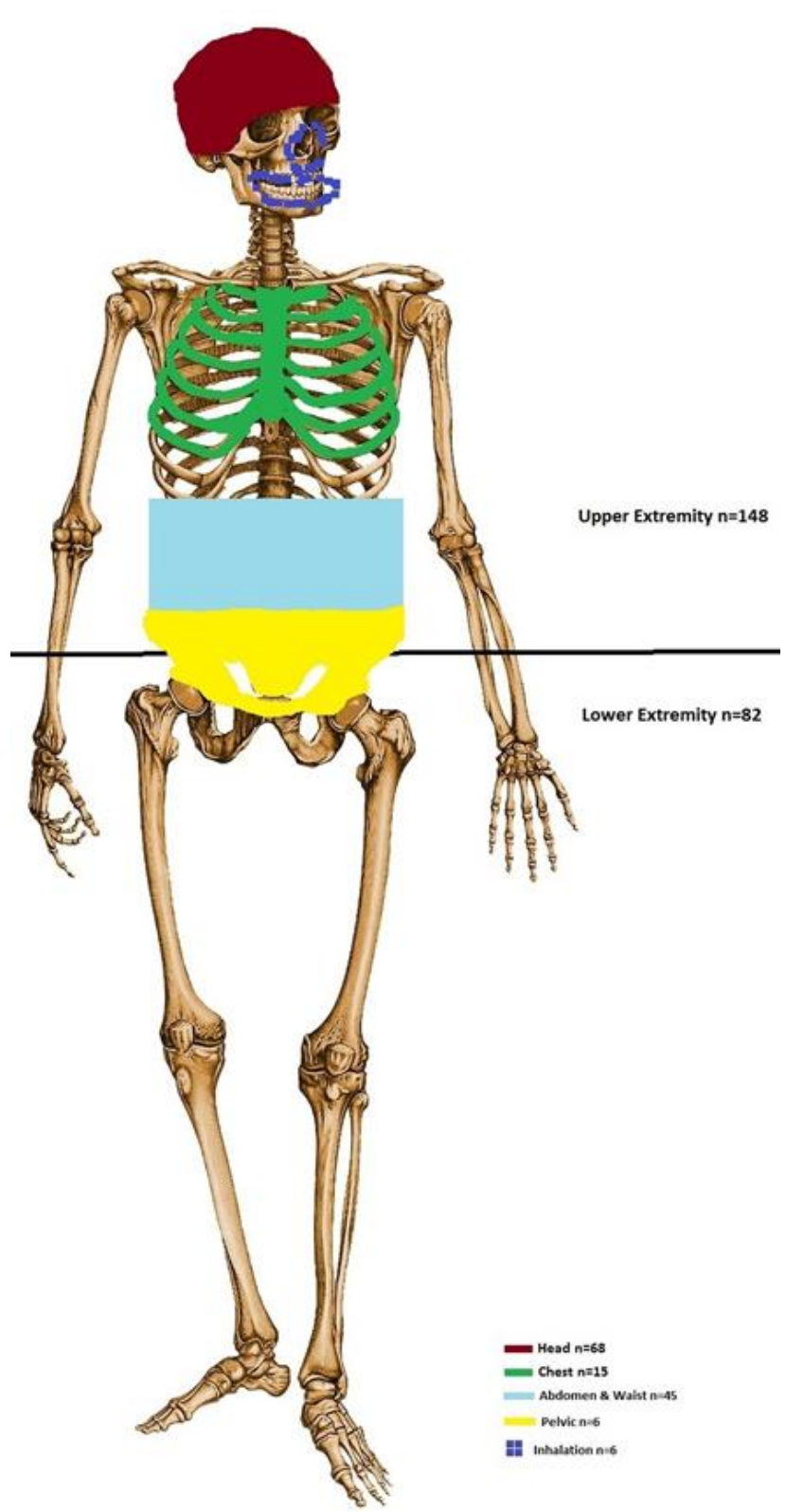

Figure 5. Injury areas on a skeleton

Discussion

In terms of occupational diseases and accidents, Turkey is one of the leading countries in the world, following Germany, Russia, America and Poland (Spada et al., 2016). In less developed and developing countries, such as Turkey, work-related injuries that may cause permanent disability and death have been increasing (Lee et al., 2005). Regarding the frequency of mining accidents, it can be observed that Turkey was the country with the second most number of accidents with 10 accidents occurring between 1970 and 1997; however, it became the country with the most accidents between 2000 and 2014 with 12 serious accidents (the most serious one was the Soma 
mining accident that resulted in the death of 301 workers in 2014) (Spada et al., 2016).

Epidemiological studies are important for the passing of necessary laws to prevent these accidents as they provide understanding of the form and nature of injuries and determine the predisposing factors that cause accidents. Thus, the purpose of this study was to collect regional data by assessing the injuries that occurred as a result of mining accidents in the Central Black Sea region.

This epidemiological study analyzed the mining accidents in Suluova, Amasya, which has an important share of the mine production in the Central Black Sea region. These results were in line with the results of Stojadinovic et al. (Stojadinovic et al., 2012) who performed a 10-year study that analyzed underground mining accidents in Serbia; that study reported upper extremity injuries were the most frequent at $35.4 \%$, followed by lower extremity injuries at $34.2 \%$. In the same study, they reported that $91 \%$ of injuries were simple injuries, i.e., mostly finger cuts and contusions, followed by severe injuries causing disability at $8.6 \%$ and fatal injuries at $0.27 \%$. In a study of Kyeremateng-Amoah and Clarke (2015) assessing the injuries in a gold mine reported that $30.5 \%$ of the patients were admitted due to fractures, while $29.1 \%$ were contusions and $14 \%$ were lacerations. Sutherland (Sutherland et al., 2011) reported contusions and lacerations were most frequent $(39.3 \%, 24.8 \%)$, followed by fractures $(10.2 \%)$ and traumatic amputations (4.7\%). In another study that assessed the risk factors in mines, it was reported that extremities were the most frequently affected areas, with knees and legs (33.3\%) affected the most (Long et al., 2015). The same study reported that cuts, lacerations and contusions were the most frequent types of injuries (80\%) (Long et al., 2015). Calys-Tagoe et al. (2015) reported that the most frequent injury areas were the extremities (upper extremity injuries were more frequent) and that the most frequent type of injury was a laceration at $57 \%$.

Our study showed that accidents can occur at any age and experience level. On the contrary to what was expected, it was found that accidents were more frequent among workers who had 10 years of experience and middle-aged workers than among those with less experience and younger workers (180, $55 \%$ ). These results were not in parallel with those from other studies in the literature that reported that less experienced mine workers had more accidents (Calys-Tagoe et al. 2015). Our result shows that preventive measures and training should be generalized in Turkey regardless of experience. In studies that were conducted on different dates to determine the reasons for work-related accidents in Turkey, it was concluded that in general, $80 \%$ of work-related accidents occurred due to human factors, $18 \%$ occurred due to physical and mechanical environmental factors and $2 \%$ occurred due to unexpected events (Camkurt et al., 2007).

Although most of the injuries were dependent on human factors (physiological, psychological, social), demographic factors (age, gender), injury time (hour, day, season), area and the number of injuries can also affect morbidity and mortality. Field studies indicated that people who work on rotating shifts and these variabilities are at a high risk for involvement in accidents and injuries (De Araújo Fernandes et al., 2013). It was observed that more than half of the injuries took place during the 08 am to $5 \mathrm{pm}$ shift. The reason for this may be the fact that the mining work, the operations and all service and maintenance work are mostly performed during the first shift of the morning. We think that the miners in the first shift work as quickly as possible to avoid causing delays and problems for the second and third shifts, which may lead to accidents and injuries. In their 10-year study on underground mining accidents in Serbia, Stojadinovic et al. (2012) also reported that the greatest number of accidents occurred during the first shift for all years and that the average percentage of accidents during this shift was $44.5 \%$. These results are similar to the results of our study. In their study about hand injuries, Davas Aksan et al. (Davas Aksan et al., 2010) reported that most patients were admitted to the hospital on a Monday, while patients were least frequently admitted on Sundays.

The limitations of our study include its retrospective design, the fact that the results came from the emergency service of only one hospital and the relatively small number of cases. The results of the study can be affected by simple injuries, which are not taken to hospital, unrecorded accidents that resulted in deaths or the number of miners who worked without insurance. However, despite all of these limitations, we believe that this study provides information about the epidemiology and severity of mining accidents in Turkey.

\section{Conclusion}

In conclusion, mining accidents cause serious injuries and deaths in developing countries such as Turkey. More extensive studies that characterize the rates, severity, risk factors and the socioeconomic results of such injuries are required. We believe that the establishment of a large-scale study that includes 
these types of studies from all over the world will contribute to the prevention of mining accidents.

Ethics Committee Approval: Ethics committee approval was received for this study from School of Medicine Clinical Research Ethics Committee of Ondokuzmayıs

(B.30.2.ODM.0.20.08/1187)

Peer-review: Externally peer-reviewed.

Author Contributions: Concept EU,AÇ,ÖŞ,SÖ,FK,HG ； Design EU,AÇ,ÖŞ; Supervision AÇ,ÖŞ,SÖ,FK,HG; Materials EU,AÇ,ÖŞ; Data Collection and/or Processing ÖŞ,SÖ,FK,HG.; Analysis and/or Interpretation AÇ,ÖŞ,SÖ; Literature Review - EU,AÇ,ÖŞ,SÖ,FK; Writing - EU,AÇ; Critical Review - AÇ,HG.

Conflict of Interest: No conflict of interest was declared by the authors.

Financial Disclosure: The authors declared that this study hasn't received no financial support.

\section{References}

Bio FY, Sadhra S, Jackson C, Burge PS. Low back pain in underground gold miners in Ghana. Ghana Med J 2007; 41: 21-5.

Bloch K, Johnson LF, Nkosi M, Ehrlich R. Precarious transition: A mortality study of South African exminers. BMC Public Health 2018; 18: 862.

Calys-Tagoe BN, Ovadje L, Clarke E, Basu N, Robins T. Injury Profiles Associated with Artisanal and Small-Scale Gold Mining in Tarkwa, Ghana. Int J Environ Res Public Health 2015; 12: 7922-37.

Camkurt MZ. İşyeri Çalışma Sistemi ve İşyeri Fiziksel Faktörlerinin İs Kazaları Üzerindeki Etkisi. TUHIS İş Hukuku ve İktisat Dergisi 2007; 20: 80-106.

Davas Aksan A, Durusoy R, Ada S, Kayalar M, Aksu F, Bal E. Epidemiology of injuries treated at a hand and microsurgery hospital. Acta Orthop Traumatol Turc 2010; 44: 352-60.

De Araújo Fernandes S Jr, Stetner Antonietti L, Saba A, Paulino de Faria A, Maculano Esteves A, Tufik S, Túlio de Mello M. The Impact of Shift Work on Brazilian Train Drivers with Different Chronotypes: A Comparative Analysis Through Objective and Subjective Criteria. Med Princ Pract 2013; 22: 390-6.

Feyer AM, Williamson AM, Stout N, Driscoll T, Usher H, Langley JD. Comparison of work-related fatal injuries in the United States, Australia, and
New Zealand: method and overall findings. Inj Prev 2001; 7: 22-8.

Ghosh AK, Bhattacherjee A, Chau N. Relationships of working conditions and individual characteristics to occupational injuries: a casecontrol study in coal miners. J Occup Health 2004; 46: 470-80.

Komljenovic D, Groves WA, Kecojevic VJ. Injuries in U.S. mining operations-a preliminary risk analysis. Safety Science 2007; 46: 792-801.

Kowalski-Trakofler KM, Barrett EA. The concept of degraded images applied to hazard recognition training in mining for reduction of lost-time injuries. J Safety Res 2003; 34: 515-25.

Kunda R, Frantz J, Karachi F. Prevalence and Ergonomic Risk Factors of Work-related Musculoskeletal Injuries amongst Underground Mine Workers in Zambia. J Occup Health 2013; 55: 211-7.

Kyeremateng-Amoah E, Clarke EE. Injuries among Artisanal and Small-Scale Gold Miners in Ghana. Int J Environ Res Public Health 2015; 12: 1088696.

Lee HY, Yeh WY, Chen CW, Wang JD. Prevalence and psychosocial risk factors of upper extremity musculoskeletal pain in industries of Taiwan: a national wide study. J Occup Health 2005; 47: 311-8.

Liu L, Wen F, Xu X, Wang L. Effective resources for improving mental health among Chinese underground coal miners: Perceived organizational support and psychological capital. J Occup Health 2015; 57: 58-68.

Long RN, Sun K, Neitzel RL. Injury Risk Factors in a Small-Scale Gold Mining Community in Ghana's Upper East Region. Int J Environ Res Public Health 2015; 12: 8744-61.

Maiti J, Chatterjee S, Bangdiwala SI. Determinants of work injuries in mines-an application of structural equation modeling. Inj Control Safety Promot 2004; 11: 29-37.

McGwin G Jr, Valent F, Taylor AJ, Howard HJ , Davis GG , Brissie RM , Rue LW 3rd. Epidemiology of fatal occupational injuries in Jefferson County, Alabama. South Med J 2002; 95: 1300-11.

Spada M, Burgherr P. An aftermath analysis of the 2014 coal mine accident in Soma, Turkey: Use of risk performance indicators based on historical experience. Accident Analysis and Preventation 2016; 87: 134-40.

Stojadinovic S, Syrkota I, Petrovic D, Denic M, Pantovic R, Milic V. Mining injuries in Serbian 
underground coal mines-a 10-year study. Injury 2012; 43: 2001-5.

Sutherland DKB. Occupational injuries in a gold mining company in Ghana. Afr Newwslerr Occup Health and Saf 2011; 21: 8-10.

Trybus M, Lorkowski J, Brongel L, Hladki W. Causes and consequences of hand injuries. Am J Surg 2006; 192: 52-7.

Wilson KS, Kootbodien T, Naicker N. Excess Mortality Due to External Causes in Women in the South African Mining Industry: 2013-2015. Int J Environ Res Public Health 2020: 13; 17(6) E1875.

Wilson K. and Vetten M. National Institute for Occupational Health Research Day 2018. Occup Health S Afr 2019; 25: 24-34. 